\title{
Control failure of Sri Lankan whitefly (Bemisia tabaci Genn.) is due to high resistance development against recommended insecticides
}

\author{
J.P. Marasinghe ${ }^{1}$, K.S. Hemachandra ${ }^{2}$, L. Nugaliyadde ${ }^{3}$ and S.H.P.P. Karunaratne ${ }^{4,5^{*}}$ \\ ${ }^{1}$ Horticulture Research and Development Institute, Department of Agriculture, Peradeniya. \\ 2 Department of Agricultural Biology, Faculty of Agriculture, University of Peradeniya, Peradeniya. \\ ${ }^{3}$ Sri Lanka Organization of Agriculture Professionals, Department of Agriculture, Peradeniya. \\ ${ }^{4}$ Department of Zoology, Faculty of Science, University of Peradeniya, Peradeniya. \\ ${ }_{5}^{5}$ National Institute of Fundamental Studies, Hantana Road, Kandy.
}

\begin{abstract}
Whitefly, Bemisia tabaci Genn. is a major pest of vegetables. Control of the whitefly has become a major problem in agriculture pest control programmes despite the use of several recommended insecticides. No studies have been carried out previously in Sri Lanka to evaluate the insecticide resistance status of $B$. tabaci. The present study focused on identifying the resistance status of $B$. tabaci from three main climatic zones of Sri Lanka. Field collected or laboratory reared (up to $5^{\text {th }}$ generation) adults from Gannoruwa $(\mathrm{n}=3612)$, Kahatagasdigiliya $(n=3385)$ and Bandarawela $(n=4146)$ were exposed to different concentrations of recommended insecticides, i.e. two neonicotinoids (thiamethoxam and acetamiprid), an organophosphate (profenofos), a carbamate (carbosulfan) and a pyrethroid (etofenprox), using leaf-dip method. Log-probit mortality curves were obtained for each insecticide, and compared with published data available for susceptible populations and the dosages recommended by the Department of Agriculture (DOA) of Sri Lanka. Resistance factors (RF) ranged from $2.74-789.48$ and the highest resistance was observed for etofenprox. Moderate to high resistance to neonicotinoids and moderate resistance to carbosalfan was evident. All three populations were largely susceptible for profenofos. The populations exhibited significant heterogeneous responses at least for one insecticide except for carbosulfan. A 6 to 800 fold increase of the DOA recommended dosages are needed to gain $90 \%$ mortality of the populations except for profenofos. An integrated approach to manage insecticide resistance guided with a regular resistance monitoring programmes is urgently required for effective control of the whitefly in horticultural crops in Sri Lanka.
\end{abstract}

Keywords: Agricultural pests, Bemisia tabaci G., insecticide resistance, log-probit mortality curves, WFRM.

\section{INTRODUCTION}

Whitefly, Bemisia tabaci Genn. (Aleyrodidae: Hemiptera) is a serious pest that is used to be controlled by insecticides in many horticultural crops including beans, brinjal, tomato, cucurbits and ornamental plants in Sri Lanka. Nymphs and adults of $B$. tabaci feed on the lower surface of the leaves and remove plant sap causing loss of vigour of the plants under severe infestations. It secretes honey dew and spreads many viruses causing a significant economic loss to the grower. Due to the wide host range of the pest and prevailing overlapping cropping pattern, a well-planned year round programme is needed to control whiteflies. Neonicotinoids (thiametoxam, acetamiprid and imidacloprid), organophosphates, carbamates and pyrethroids are used as integral tools for the management of whiteflies all over the world (Caballero et al., 2013). In Sri Lanka, thaimethoxam, acetamiprid, carbosulfan and profenofos have been recommended by the Department of Agriculture (DOA) for the control of whiteflies. Some other insecticides such as etofenprox are also applied by farmers to their crops infested with whiteflies, although these chemicals have not been recommended specifically for whitefly control.

Multiple applications of insecticides create a selection pressure for resistance development in the field populations of whitefly (Palumbo et al., 2001; Caballero et al., 2013) leading to the appearance of different biotypes (Horowitz et al., 2005). B. tabaci has been ranked as the

"Corresponding author (shppk@pdn.ac.lk) 
$5^{\text {th }}$ top resistant insect species among agricultural insect pests, being resistant to 54 insecticide compounds with 555 recorded cases throughout the world (Sparks \& Nauen, 2015). Acetamiprid, thiamethoxam, profenofos, carbosulfan and etofenprox are among the compounds to which reduced susceptibility levels have been detected (Li et al., 2000; Farghaly, 2010; Houndete et al., 2010).

Insecticide resistance in a population is commonly measured by calculating the resistance factor (RF), which is the ratio of $\mathrm{LC}_{50}$ between a test population and a known susceptible population. A RF of 10 or greater has been used as a threshold to declare a resistance development (Mota-Sanchez et al., 2008). Discriminating dosages or resistance diagnostic dosages, which are supposed to kill all the susceptible individuals leaving the resistant ones, have also been used to determine the resistance (Mota-Sanchez et al., 2008). This diagnostic dosage can be used to differentiate the homozygous susceptible (SS) individuals from homozygous resistant (RR) and heterozygous resistant (RS) individuals for a particular insecticide.

Knowledge on the resistance status of a particular insect pest is vital to evaluate the validity of the insecticides in use and their recommended dosages, in order to achieve effective management of the pest. Insecticide resistance management (IRM) is a group of strategies that helps to maintain the susceptibility status of insects to available insecticides, and maintain their effectiveness by preventing or delaying the development of resistant strains (Tejeda et al., 2009). Thus, the data obtained from resistance studies are essential for integrated IRM programmes for an effective pest management with a minimum risk to health and environment.

In this study, we report the resistance status of three whitefly populations collected from the Wet (annual rainfall $>2,500 \mathrm{~mm}$ ), Dry (annual rainfall $<1,750 \mathrm{~mm}$ ) and Intermediate (annual rainfall 1,750 - 2,500 mm) Zones of Sri Lanka to thiamethoxam, acetamiprid, etofenprox, carbosulfan and profenofos. Compounds from each of the major classes of insecticides were evaluated in order to find out whether the whitefly populations have developed broader resistance spectrum to different insecticide classes.

\section{METHODOLOGY}

\section{Whiteflies}

Three populations of the whitefly, B. tabaci were collected from the agricultural fields of Gannoruwa in the Wet Zone, Kahatagasdigiliya in the Dry Zone and Bandarawela in the Intermediate Zone of Sri Lanka during mid 2014 to mid 2015. The adult flies were collected to plastic vials using aspirators, from brinjal, tomato and bean crops. They were chilled and transported to the Entomology Laboratory of the Horticulture Research and Development Institute at Gannoruwa and reared in separate fine mesh aluminium cages of $80 \times 40 \times$ $60 \mathrm{~cm}$ under room temperature. Potted brinjal, tomato and cucumber plants $(2-8$ weeks $)$ placed in the cages served as host plants for the whiteflies.

\section{Insecticide bioassays}

Two neonicotinoid insecticides (thiamethoxam $25 \%$ WG and acetamiprid $20 \% \mathrm{SP}$ ), an organophosphate (profenofos $500 \mathrm{~g} / \mathrm{L} \mathrm{EC),} \mathrm{a} \mathrm{carbamate} \mathrm{(carbosulfan}$ $200 \mathrm{~g} / \mathrm{L} \mathrm{SC}$ ) and a pyrethroid (etofenprox $100 \mathrm{~g} / \mathrm{L}$ EC) were used for insecticide bioassays. The leaf dip method, as modified by the Insecticide Resistance Action Committee (IRAC, 2009), was adopted as it is closely related to the exposure pattern of the recommended foliar spraying.

Immature brinjal leaves were cut into square shapes of $3 \times 3 \mathrm{~cm}^{2}$ with petioles dipped in different concentrations of commercial formulations of the insecticides for $5 \mathrm{~s}$ and left to air dry approximately for $30 \mathrm{mins}$. Insecticide dilutions were prepared in distilled water and the dosages giving mortality between $0-100 \%$ were determined after a preliminary range finding study. The leaves dipped in distilled water alone served as the controls. The insects were exposed to the insecticide treated leaves inside transparent yoghurt cups. Prior to the assay a portion of the centre of the lid $\left(4 \mathrm{~cm}\right.$ diameter) and a portion of one side $\left(2 \times 4 \mathrm{~cm}^{2}\right)$ of the cup were removed to cover with fine net cloth for proper ventilation. The petiole of a leaf was inserted through a small tight hole made at the base of the cup, and the tip of the petiole coming out of the cup was covered with a swab of moistened cotton wool. About 30 male and female adult whiteflies were introduced into each cup through the side opening for each assay. Each treatment was replicated three times and the mortalities were recorded after $24 \mathrm{hrs}$.

Data were taken only if the control mortalities were less than $20 \%$ and the actual mortalities of test experiments were corrected with control mortalities using the Abbott's formula (Abbott, 1987). Active ingredient concentration present in each dilution was calculated using the information given in the label of each insecticide formulation. Percentage mortalities (probability axis) were plotted against the concentration 
of the active ingredient (log axis). Lethal concentration, which kills $50 \%$ of the population $\left(\mathrm{LC}_{50}\right)$ and $90 \%$ of the population $\left(\mathrm{LC}_{90}\right)$, slope of the mortality curve, $95 \%$ confidence interval, chi square at 0.05 probability, and correlation coefficient $\left(\mathrm{r}^{2}\right)$ were obtained by probit analysis using Sigma Plot (Version 10.0) software.

Table 1 shows the dosages of thiamethoxam, acetamiprid, profenofos and carbosulfan recommended by the Department of Agriculture (DOA), Sri Lanka for whitefly control. Mortalities for these concentrations of the active ingredients were obtained for Gannoruwa, Kahatagasdigiliya and Bandarawela populations using log-probit mortality curves. A DOA recommendation for whitefly control for etofenprox was not available; therefore recommended dosages for the control of sucking insects of the same family were used. Since a susceptible local whitefly population or reported data on a local susceptible whitefly population could not be found, $\mathrm{LC}_{50}$ values available for susceptible populations and discriminating dosages for neonicotinoids and

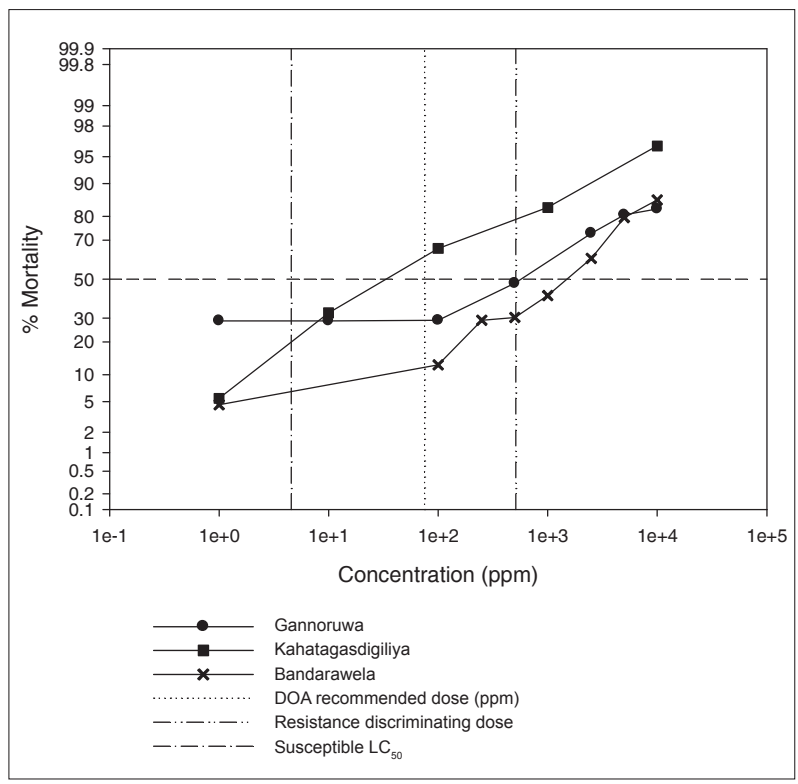

Figure 1: Log-probit mortality curves for the whitefly populations from Gannoruwa $(n=647)$, Kahatagasdigiliya $(n=685)$ and Bandarawela $(n=701)$ exposed to thiamethoxam using bioassays by leaf-dip method. Dosage recommended by the DOA for whitefly control in Sri Lanka, $\mathrm{LC}_{50}$ for a susceptible population (Vassiliou, 2011) and a resistance discrimination dosage (Huang et al., 2007) are also shown for comparison. pyrethroid insecticides from elsewhere were used to calculate the resistance factors (RF).

Table 1: Insecticides and their dosages recommended by the DOA for the control of whitefly in Sri Lanka

\begin{tabular}{lccc}
\hline Insecticide & $\begin{array}{c}\text { Mode of } \\
\text { action }^{\text {a }}\end{array}$ & $\begin{array}{c}\text { Recommended } \\
\text { dosage/ 10 L }\end{array}$ & $\begin{array}{c}\text { A.I.C. }^{b} \\
(\mathrm{ppm})\end{array}$ \\
\hline Thiamethoxam 25 WG & $4 \mathrm{~A}$ & $5 \mathrm{~g}$ & 125 \\
Acetamiprid 20 SP & $4 \mathrm{~A}$ & $10 \mathrm{~g}$ & 200 \\
Profenofos 50 EC & $1 \mathrm{~B}$ & $20 \mathrm{~mL}$ & 1000 \\
Carbosulfan 20 EC & $1 \mathrm{~A}$ & $30 \mathrm{~mL}$ & 600 \\
\hline
\end{tabular}

${ }^{\mathrm{a}}$ As listed by the Insecticide Resistance Action Committee: $4 \mathrm{~A}=$ nicotinic acetylcholine receptor competitive modulators - neonicotinoids; $1 \mathrm{~B}=$ acetylcholinesterase inhibitors - organophosphates; $1 \mathrm{~A}=$ acetylcholinesterase inhibitors - carbamates

${ }^{\mathrm{b}}$ A.I.C. $=$ Active ingredient concentration in the DOA recommended dosage

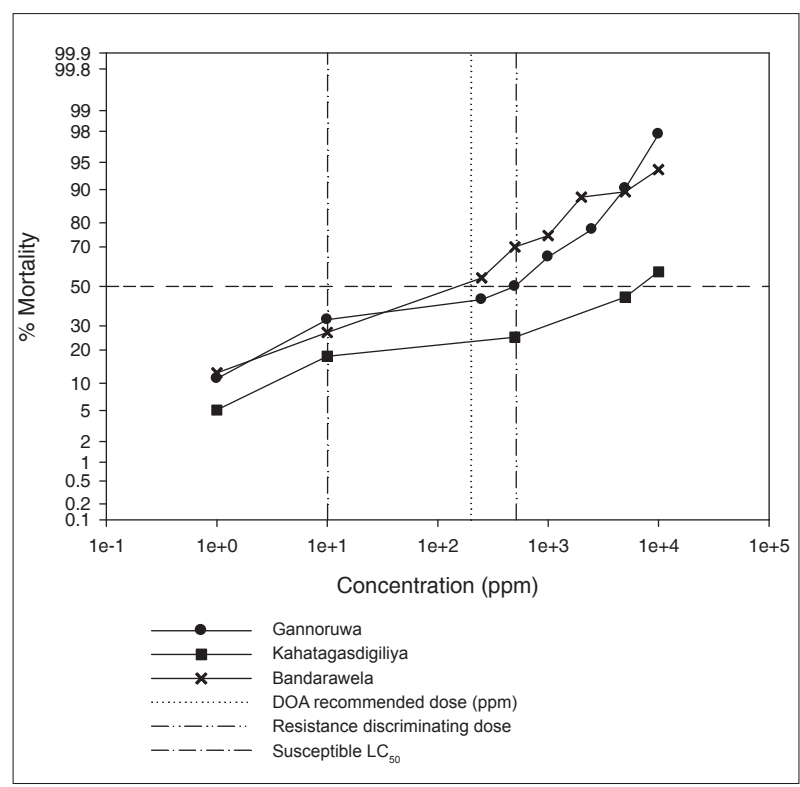

Figure 2: Log-probit mortality curves for the whitefly populations from Gannoruwa $(n=1028)$, Kahatagasdigiliya $(n=364)$ and Bandarawela $(\mathrm{n}=951)$ exposed to acetamiprid using bioassays by leaf-dip method. Dosage recommended by the DOA for whitefly control in Sri Lanka, $\mathrm{LC}_{50}$ for a susceptible population (Vassiliou, 2011) and a resistance discrimination dosage (Huang et al., 2007) are also shown for comparison. 


\section{RESULTS AND DISCUSSION}

Bioassay data with mortalities between $0-100 \%$ were successfully obtained for different concentrations of the insecticides for all three populations of whiteflies. Logconcentration probability-mortality curves for all three insect populations for the insecticides tested are shown in Figures $1-5$. The results of the probit analysis are given in Tables 2 and 3.

For thiamethoxam $\mathrm{LC}_{50}$ ranged from 53.11 $1088.43 \mathrm{ppm}$. If the mortality curve is fitted into a linear curve, the population is considered as a homogeneous population (Karunaratne et al., 2007). Linearity of the curve (response to different concentrations) was rejected for Gannoruwa and Bandarawela populations indicating the heterogeneity of these populations. The highest heterogeneity was observed in Gannoruwa population $(\mathrm{p}<0.001$; Figure 1). All three populations showed a high resistance $(\mathrm{RF}>10)$ with the highest shown by the Bandarawela population $(\mathrm{RF}=238.69)$. At the dosage recommended by the DOA, thiamethoxam has shown a low efficacy giving a mortality between $26.01 \%$ and $61.59 \%$. According to the estimations, the recommended dosage has to be increased by $\times 16, \times 566$ and $\times 800$ folds to obtain $90 \%$ mortality of Kahatagasdigiliya, Bandarawela and Gannoruwa populations, respectively.

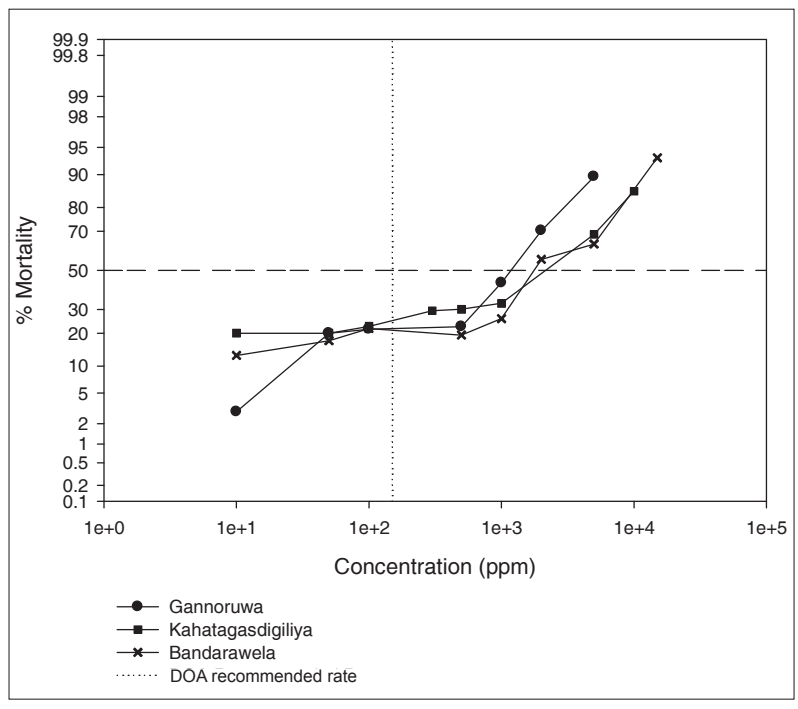

Figure 3: Log-probit mortality curves for the whitefly populations from Gannoruwa $(n=821)$, Kahatagasdigiliya $(n=925)$ and Bandarawela $(\mathrm{n}=982)$ exposed to etofenprox using bioassays by leaf-dip method. Dosage recommended by the DOA for whitefly control in Sri Lanka, is also shown for comparison.
$\mathrm{LC}_{50}$ of acetamiprid ranged from $11.55-21.80 \mathrm{ppm}$. Linearity of the mortality response to the concentration was rejected for Gannoruwa population, which exhibited the highest heterogeneity ( $<0.01$; Figure 2 ). Gannoruwa and Kahatagasdigiliya populations showed a high resistance $(\mathrm{RF}>10)$ with the highest by Kahatagasdigiliya $(\mathrm{RF}=789.48)$. Mortality estimated for the DOA recommended dosage of acetamiprid ranged from $26.59 \%$ to $56.59 \%$ showing a low efficacy. To achieve $90 \%$ mortality $\times 30, \times 45$ and $\times 500$ fold increase of the recommended dosage of the insecticide is needed for Bandarawela, Gannoruwa and Kahatagasdigiliya populations, respectively.

The $\mathrm{LC}_{50}$ range of etofenprox for the three populations was $749.89-1270.57 \mathrm{ppm}$. Linearity of the mortality curve was rejected in all three cases tested and a high heterogeneity was exhibited $(\mathrm{p}<0.001)$. Resistance factors could not be established for etofenprox due to the unavailability of $\mathrm{LC}_{50}$ value for a susceptible population. At the DOA recommended dosage, the estimated mortality was very low for all three populations ranging from $24.21 \%$ to $29.69 \%$. The recommended dosage of etofenprox has to be increased by $\times 93, \times 476$ and $\times 666$ folds to obtain $90 \%$ mortality of Gannoruwa, Bandarawela and Kahatagasdigiliya populations, respectively.

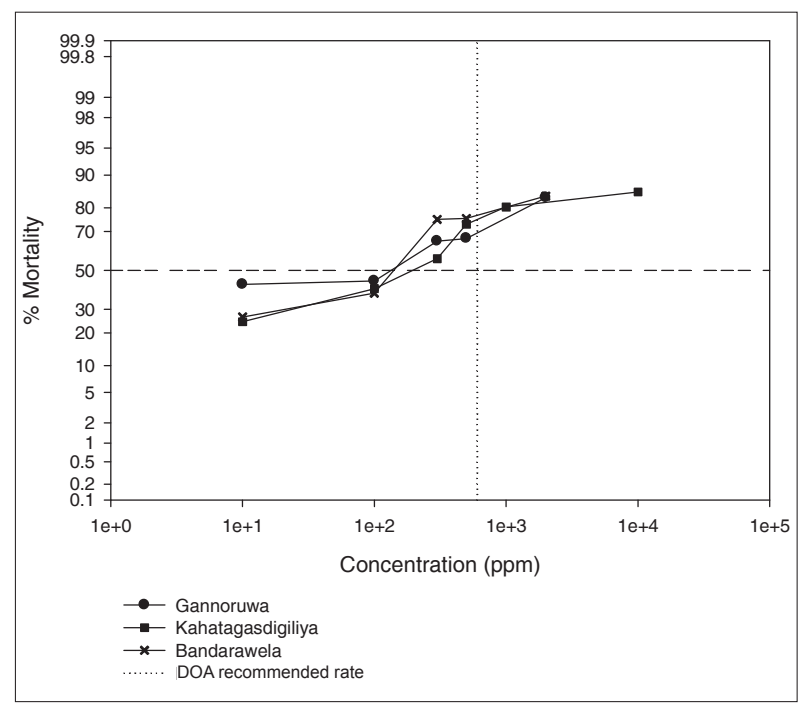

Figure 4: Log-probit mortality curves for the whitefly populations from Gannoruwa $(n=469)$, Kahatagasdigiliya $(n=726)$ and Bandarawela $(\mathrm{n}=811)$ exposed to carbosulfan using bioassays by leaf-dip method. Dosage recommended by the DOA for whitefly control in Sri Lanka, is also shown for comparison. 
Table 2: Analysis of mortality data resulted from the bioassay experiments by leaf-dip method for B. tabaci populations exposed to different dosages of neonicotinoids thiamethoxam and acetamiprid, organophosphate profenofos, carbamate carbosulfan and pyrethroid etofenprox

\begin{tabular}{|c|c|c|c|c|c|c|c|}
\hline Insecticide & $\mathrm{L}$ & $\mathrm{N}$ & $\begin{array}{c}\mathrm{LC}_{50} \\
(\mathrm{ppm})\end{array}$ & $95 \% \mathrm{CI}$ & Slope & $\chi^{2}(\mathrm{df})$ & $r^{2}$ \\
\hline \multirow[t]{3}{*}{ Thiamethoxam } & G & 647 & 141.25 & $14.98-1029.91$ & 15.39 & ${ }^{* *} 17.88(6)$ & 0.81 \\
\hline & K & 685 & 53.11 & $25.11-108.94$ & 23.23 & $2.32(4)$ & 0.98 \\
\hline & $\mathrm{B}$ & 701 & 1088.43 & $387.25-3650.90$ & 20.97 & ${ }^{*} 14.32(7)$ & 0.87 \\
\hline \multirow[t]{3}{*}{ Acetamiprid } & G & 1028 & 115.45 & $21.16-375.66$ & 20.62 & $* 15.69(7)$ & 0.93 \\
\hline & K & 364 & 7957.93 & $1189.05>100000$ & 11.55 & $4.6(4)$ & 0.85 \\
\hline & $\mathrm{B}$ & 951 & 72.97 & $46.00-115.45$ & 21.80 & $2.49(7)$ & 0.97 \\
\hline \multirow[t]{3}{*}{ Etofenprox } & G & 821 & 749.89 & $323.59-2488.86$ & 29.81 & ${ }^{* *} 18.91(6)$ & 0.88 \\
\hline & K & 925 & 1101.54 & $331.89-11272.00$ & 21.70 & ${ }^{* *} 20.67(7)$ & 0.78 \\
\hline & $\mathrm{B}$ & 982 & 1270.57 & $374.11-8260.38$ & 23.84 & ${ }^{* *} 29.19(7)$ & 0.76 \\
\hline \multirow[t]{3}{*}{ Carbosulfan } & G & 469 & 54.82 & $33.11-2293.76$ & 18.64 & $4.05(4)$ & 0.89 \\
\hline & $\mathrm{K}$ & 726 & 123.88 & $33.96-294.44$ & 22.54 & $3.06(5)$ & 0.91 \\
\hline & $\mathrm{B}$ & 811 & 82.41 & $7.85-266.68$ & 28.17 & $5.95(4)$ & 0.83 \\
\hline \multirow[t]{3}{*}{ Profenofos } & G & 647 & 5.4800 & $<0.1-34.04$ & 21.51 & 3.14 (4) & 0.83 \\
\hline & K & 685 & 8.4500 & $0.43-50.00$ & 21.96 & $11.12(6)$ & 0.81 \\
\hline & B & 701 & 6.6500 & $0.44-22.08$ & 25.93 & ${ }^{* *} 15.95(5)$ & 0.89 \\
\hline
\end{tabular}

L - location; G - Gannoruwa; K - Kahatagasdigiliya; B - Bandarawela; N - number tested; $\mathrm{LC}_{50}$ - lethal concentration which kills $50 \%$ of the population; CI - confidence interval; $\chi^{2}$ - Chi square goodness-of-fit for concentration-mortality response; df - degrees of freedom; ${ }^{*} \mathrm{p}<0.01 ;{ }^{* *} \mathrm{p}<0.001 ; \mathrm{r}^{2}$ - correlation coefficient

Table 3: Characterisation of mortality data obtained for whitefly populations exposed to the insecticides thiamethoxam, acetamiprid, etofenprox, carbosulfan and profenofos

\begin{tabular}{llrlllll}
\hline Insecticide & $\mathrm{L}$ & $\begin{array}{r}\mathrm{LC}_{50} \\
(\mathrm{ppm})\end{array}$ & $\begin{array}{l}\mathrm{LC}_{50}-\mathrm{S} \\
(\mathrm{ppm})\end{array}$ & $\mathrm{RF}$ & $\begin{array}{c}\mathrm{LC}_{90} \\
(\mathrm{ppm})\end{array}$ & $\% \mathrm{M}$ & $\begin{array}{c}\mathrm{RDD} \\
(\mathrm{ppm})\end{array}$ \\
\hline \multirow{2}{*}{ Thiamethoxam } & $\mathrm{G}$ & 141.25 & $4.56^{*}$ & 30.97 & $>100000$ & 49.29 & 512 \\
& $\mathrm{~K}$ & 53.11 & $4.56^{*}$ & 11.64 & 1939.10 & 61.59 & 512 \\
Acetamiprid & $\mathrm{B}$ & 1088.43 & $4.56^{*}$ & 238.69 & 70794.60 & 26.01 & 512 \\
& $\mathrm{G}$ & 115.459 & $10.08^{*}$ & 11.45 & 8912.51 & 56.59 & 512 \\
& $\mathrm{~K}$ & 7957.93 & $10.08^{*}$ & 789.48 & $>100000$ & 26.59 & 512 \\
Etofenprox & $\mathrm{B}$ & 72.97 & $10.08^{*}$ & 7.23 & 5953.88 & 26.59 & 512 \\
& $\mathrm{G}$ & 749.89 & $\mathrm{~N} / \mathrm{A}$ & - & 13995.99 & 24.21 & N/A \\
& $\mathrm{K}$ & 1101.54 & $\mathrm{~N} / \mathrm{A}$ & - & $>100000$ & 29.69 & N/A \\
Carbosulfan & $\mathrm{B}$ & 1270.57 & $\mathrm{~N} / \mathrm{A}$ & - & 71449.60 & 24.21 & N/A \\
& $\mathrm{G}$ & 54.82 & $\mathrm{~N} / \mathrm{A}$ & - & 18620.90 & 69.01 & N/A \\
& $\mathrm{K}$ & 123.88 & $\mathrm{~N} / \mathrm{A}$ & - & 12078.10 & 75.17 & N/A \\
Profenofos & $\mathrm{B}$ & 82.41 & $\mathrm{~N} / \mathrm{A}$ & - & 3828.25 & 76.92 & N/A \\
& $\mathrm{G}$ & 5.48 & $2.0 * *$ & 2.74 & 344.82 & 94.51 & N/A \\
& $\mathrm{K}$ & 8.45 & $2.0 * *$ & 4.23 & 344.82 & 95.46 & N/A \\
& $\mathrm{B}$ & 6.65 & $2.0 * *$ & 3.32 & 167.64 & 98.42 & N/A \\
\hline
\end{tabular}

$\mathrm{LC}_{50}-\mathrm{S}: \mathrm{LC}_{50}$ susceptible population values from *Vassiliou, 2011 and ${ }^{* *} H u a n g$ et al., 2007; N/A: not available; RF: resistance factor; \% M: \% mortality at DOA recommended dilution rate; RDD: resistance discriminating dosage values from Huang et al., 2007 


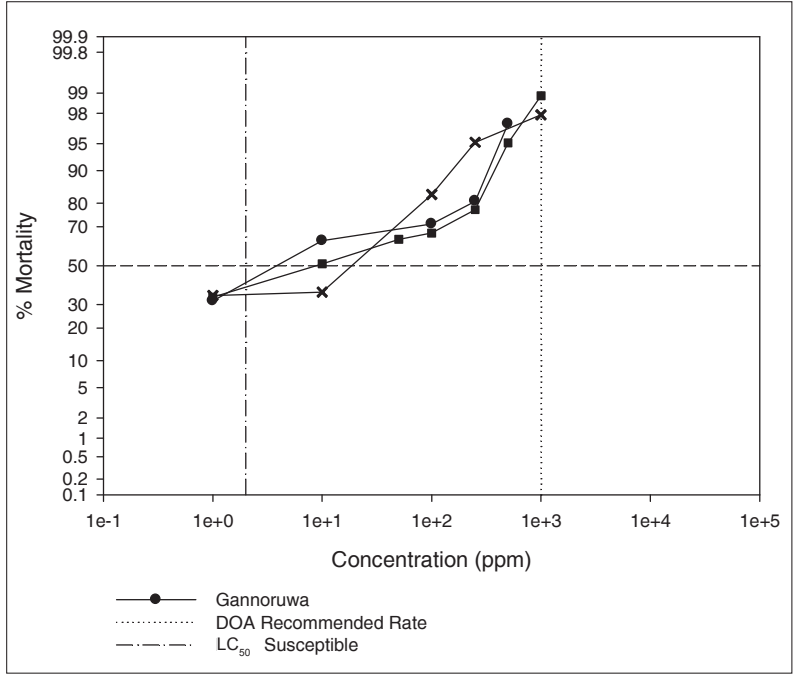

Figure 5: Log-probit mortality curves for the whitefly populations from Gannoruwa $(n=469)$, Kahatagasdigiliya $(n=685)$ and Bandarawela $(n=701)$ exposed to profenofos using bioassays by leaf-dip method. Dosage recommended by the DOA for whitefly control in Sri Lanka, and $\mathrm{LC}_{50}$ for a susceptible population (Huang et al., 2007) are also shown for comparison.

Linearity of the mortality curves was not rejected with all three populations suggesting the homogeneity of the response to carbosulfan by the three populations $(\mathrm{p}>0.05)$. The $\mathrm{LC}_{50}$ range was between 54.82 - $123.88 \mathrm{ppm}$. Resistance factors could not be established for carbosulfan due to the unavailability of $\mathrm{LC}_{50}$ value for a susceptible population. A moderate level of resistance with a mortality rate of $69.01 \%$ to $76.92 \%$ could be achieved at the DOA recommended dosage for carbosulfan. A $\times 6, \times 20$ and $\times 3$ fold increase of the recommended dosage is needed to kill $90 \%$ of the Bandarawela, Kahatagasdigiliya and Gannoruwa populations, respectively.

For profenofos, mortality response of the Bandarawela population was not linear $(\mathrm{p}<0.001)$ and the $\mathrm{LC}_{50}$ values ranged from $5.48-8.45 \mathrm{ppm}$. All three populations exhibited low resistance factor levels. The RF values were 2.74, 3.32 and 4.23, respectively for Gannoruwa, Bandarawela and Kahatagasdigiliya populations. A high efficacy of the DOA recommended dosage for profenofos giving mortalities above $95 \%$ was observed for all three populations.

Monitoring programmes have revealed that the patterns of insecticide usage (i.e. continuous, mosaic or alternate) have a significant impact on the development of resistance in the whitefly, B. tabaci (Palumbo et al., 2001; Servin-Villegas et al., 2006; Castle \& Prabhakar, 2013) apart from the influence from host plant interactions ( $\mathrm{Li}$ et al., 2000; Castle et al., 2008), environmental stresses (Castle \& Prabhakar, 2013), and different biotypes (Dennehy et al., 2005; Li et al., 2012; Xie et al., 2014). Thus, continuous monitoring of resistance to different insecticides can detect the change of susceptibility levels in a population allowing the implementation of necessary changes to insecticide usage pattern. Insecticide resistance status of $B$. tabaci has been well documented in other countries (Denholm et al., 1998; Dennehy et al., 2004; Vassiliou et al., 2011; Xie et al., 2014). Although insecticide resistance of selected insect pests and natural enemies of rice (Hemingway et al., 1999; Karunaratne et al., 1999; 2007; Karunaratne \& Weerakoon, 2007) and horticultural crops (Damayanthi \& Karunaratne, 2005) has been reported previously from Sri Lanka, this is the first report to show the insecticide resistance status of Sri Lankan whitefly populations.

Uniform high resistance levels were observed with etofenprox in all three populations suggesting that the whitefly populations have developed resistance to this particular pyrethroid insecticide. Moderate to very high levels of resistance were observed with neonicotinoids. For carbosulfan, the resistance was moderate while for profenofos, the populations were highly susceptible. Comparison of mortality responses with those of susceptible populations of whiteflies reported for neonicotinoids by Vassiliou et al. (2011) and for profenofos by Huang et al. (2007) was possible, since the methodologies used were similar. Resistance factors could not be obtained for etofenprox and carbosulfan due to the unavailability of reported mortality data of a susceptible population. High heterogeneity was observed with all three populations for all the insecticides tested except for carbosulfan, suggesting the possible existence of different biotypes.

At present, neonicotinoids, thiamethoxam and acetamiprid are widely used for whitefly control in chili, potato, bean, cucurbits and floriculture in Sri Lanka (DOA, 2009). Outbreaks of whitefly populations were observed in the areas of Bandarawela and Kahatagasdigiliya recently, despite several repeated applications of neonicotinoids. Whitefly resistance to neonicotinoids has been reported from many countries (Vassiliou et al., 2011; Castle \& Prabhakar, 2013). The pyrethroid, etofenprox, has not been recommended for whitefly control in Sri Lanka. However the brinjal crop, which is one of the host plants from which the pest was collected for the present study, is generally sprayed with etofenprox during pest control programmes as etofenprox 
is recommended for brinjal shoot and pod borer control (DOA, 2009). Thus, it is obvious that the whiteflies are exposed to this insecticide regularly, developing the resistance. However, the Bandarawela B. tabaci population, which was collected from bean cultivations where etofenprox is not routinely applied, has also shown a high resistance level against etofenprox. Therefore, it is important to further examine the mechanism of cross resistance development to etofenprox in future studies. Whitefly resistance to etofenprox has also been reported from other countries (Cahill et al., 1995). Both carbosulfan and profenofos are recommended for the control of chili leaf curl virus vectors including whiteflies, and the farmers tend to apply these on other crops also due to the broad spectrum pest control ability of the insecticides. High effectiveness of profenofos against the whitefly as shown by the present study highlights the importance of incorporation of profenofos in whitefly resistance management (WFRM) programmes.

The underlying mechanisms for the observed differences in resistance levels, and the efficacy for carbamate and organophosphate classes need to be studied in detail as both groups share the same target site, acetylcholinesterase. Insecticide resistance of insects can be developed due to qualitative and/or quantitative changes of the insect metabolic enzyme systems and due to mutated target sites (Karunaratne, 1998). The resistance to neonicotinoids in $B$. tabaci has been associated with enhanced oxidative detoxification by cytochrome P450 mono-oxygenases (Rauch \& Nauen, 2003; Jones et al., 2011). Metabolic detoxification by esterases and monooxygenases, and target site mutations in acetylcholineesterases have been associated with insecticide resistance in B. tabaci (Alon et al., 2008; Roditakis et al., 2009). Further studies to investigate the underlying molecular mechanisms for the high insecticide resistance of whitefly populations will be useful for the future agricultural pest control programmes of Si Lanka.

According to our results, all the tested insecticides except profenofos require $\times 6$ to $\times 800$ fold increase of the recommended dosage to keep the efficacy at $90 \%$ level, which is not economically or environmentally acceptable. Repeated application of insecticides for which pests have already developed resistance, has led to further development of resistance in the whitefly populations establishing resistance genes in the populations giving high reproductive dynamics (Heong et al., 2011). An integrated approach including physical and biological control strategies together with effective insecticides followed by regular resistance monitoring programmes for whitefly control is essential for future WFRM programmes of the country.

\section{CONCLUSION}

Whitefly populations from the Wet, Intermediate and Dry Zones of Sri Lanka show high resistance to thiamethoxam, acetamiprid, carbosulfan and etofenprox demanding x 6 to $\times 800$ fold increase of the recommended dosages for a $90 \%$ mortality. Since this is not an economically or environmentally viable option, these insecticides should be removed from whitefly control programmes with immediate effect. Organophosphates can be used as alternatives. An integrated approach with effective insecticides followed by regular resistance monitoring is urgently required for effective control of whitefly populations in Sri Lanka.

\section{Acknowledgement}

This work was funded by a Research Grant to the first author by the National Agricultural Research Policy (NARP). We thank Ms G.N.G.K.S. Nawaratne for the invaluable assistance given during field and laboratory bioassays.

\section{REFERENCES}

1. Abbott W.S. (1987). A method of computing the effectiveness of an insecticide. Journal of the American Mosquito Control Association 3(2): 302 - 303.

2. Alon M., Alon F. \& Morin S. (2008). Organophosphates resistance in the B-biotype of Bemisia tabaci (Hemiptera: Aleyrodidae) is associated with a point mutation in an ace1-type acetylcholinesterase and overexpression of carboxylesterase. Insect Biochemistry and Molecular Biology 38(10): 940 - 949.

DOI: https://doi.org/10.1016/j.ibmb.2008.07.007

3. Caballero R., Cyman S. \& Schuster D.J. (2013). Monitoring insecticide resistance in biotype B of Bemisia tabaci (Hemiptera: Aleyrodidae) in Florida. Florida Entomologist 96(4): 1243 - 1256.

DOI: https://doi.org/10.1653/024.096.0402

4. Cahill M., Byrrne F.J., Gorman K., Denhil I. \& Devonshire A.L. (1995). Pyrethroid and organophosphate resistance in the tobacco whitefly Bemisia tabaci (Homoptera: Aleyrodidae). Bulletin of Entomological Research 85(2): $181-187$.

DOI: https://doi.org/10.1017/S0007485300034258

5. Castle S.J. \& Prabhakar N. (2013). Monitoring changes in Bemisia tabaci (Homoptera: Aleyrodidae) susceptibility to neonicotinoid insecticides in Arizona and California. Journal of Economic Entomology 106(3): 1404 - 1413.

6. Castle S.J., Prabhakar N., Henneberry T.J. \& Toscano N.C. (2008). Host plant influence on susceptibility of Bemisia tabaci (Hemiptera: Aleyrodidae) to insecticides. Bulletin of Entomological Research 99(3): 263 - 273.

DOI: https://doi.org/10.1017/S0007485308006329 
7. Damayanthi B.T. \& Karunaratne S.H.P.P. (2005). Biochemical characterisation of insecticide resistance in insect pests of vegetables and predatory ladybird beetles. Journal of the National Science Foundation of Sri Lanka 33(2): $115-122$.

8. Denholm I., Cahill M., Dennehy T.J. \& Horowitz A.R. (1998). Challenges with managing insecticide resistance in agricultural pests, exemplified by the whitefly Bemisia tabaci. Philosophical Transactions of the Royal Society of London B 353: 1757 - 1767.

DOI: https://doi.org/10.1098/rstb.1998.0328

9. Dennehy T.J., DeGain B.A., Harpold V.S. \& Brink S.A. (2004). Whitefly resistance to insecticides in Arizona: summary of 2002 and 2003 results. Proceedings of the Beltwide Cotton Conferences. National Cotton Council, Memphis, USA.

10. Dennehy T.J., DeGain B.A., Harpol V.S., Brown J.K., Morin S., Farbrick J.A., Byrne F.J. \& Nichols R.L. (2005). New challenges to management of whitefly resistance to insecticides in Arizona. Vegetable Report of University of Arizona. College of Agriculture and Life Sciences, Arizona, USA.

11. Department of Agriculture (DOA) (2009). Pesticide Recommendations. Department of Agriculture, Gannoruwa, Peradeniya.

12. Farghaly S.F. (2010). Biochemical monitoring for insecticides resistance in Bemisia tabaci. American Eurasian Journal of Agricultural and Environmental Science 8(4): 383 - 389.

13. Hemingway J., Karunaratne S.H.P.P. \& Claridge M.F. (1999). Insecticide resistance spectrum and underlying resistance mechanisms in tropical populations of the brown planthopper (Nilaparvata lugens) collected from rice and the wild grass Leersia hexandra. International Journal of Pest Management 45(3): 215 - 223.

DOI: https://doi.org/10.1080/096708799227824

14. Heong K.L., Tan K.H., Garcia C.P.F., Fabellar L.T. \& Lu Z. (2011). Research Methods in Toxicology and Insecticide Resistance Monitoring of Rice Plant Hoppers. Rice Plant Hopper Project, International Rice Research Institute, Manila, The Philippines.

15. Horowitz A.R., Kontsedalov S., Khasdan V. \& Ishaaya I. (2005). Biotypes B and Q of Bemisia tabaci and their relevance to neonicotinoide and pyriproxyfen resistance. Archives of Insect Biochemistry and Physiology 58: $216-225$.

DOI: https://doi.org/10.1002/arch.20044

16. Houndete T.A., Fournier D., Ketoh G.K., Glitho I.A., Nauen R. \& Martin T. (2010). Biochemical determination of acetylcholinesterase genotypes conferring resistance to the organophosphate insecticide chlorpyriphos in field populations of Bemisia tabaci from Benin, West Africa. Pesticide Biochemistry and Physiology 98(1): 115 - 120. DOI: https://doi.org/10.1016/j.pestbp.2010.05.009

17. Huang J.X., Rogers B.R., Orr N., Sparks T.C., Gifford J.M., Loso M.R., Zhu Y. \& Meade T. (2007). A method to control insects resistant to common insecticides. Patent WO 2007149134A1. Dow AgroSciences Llc.
18. Insecticide Resistance Action Committee (IRAC) (2009). IRAC Susceptibility Test Methods Series, method No. 008, version 3. Available at www. irac-online.org.

19. Jones C.M., Daniels M., Andrews M., Slater R., Lind R.J., Gorman K., Williamson M.S. \& Denholm I. (2011). Age specific expression of a P-450 monooxygenase (CYP6CM1) correlates with neonicotinoid resistance in Bemisia tabaci. Pesticide Biochemistry and Physiology 10: $53-58$.

DOI: https://doi.org/10.1016/j.pestbp.2011.07.004

20. Karunaratne S.H.P.P. (1998). Insecticide resistance in insects: a review. Ceylon Journal of Science (Biological Sciences) 25: $72-99$.

21. Karunaratne S.H.P.P., Small G.J. \& Hemingway J. (1999). Characterisation of the elevated esterase-associated insecticide resistance mechanism in Nilaparvata lugens Stal and other planthopper species. International Journal of Pest Management 45(3): 225 - 230.

DOI: https://doi.org/10.1080/096708799227833

22. Karunaratne S.H.P.P. \& Weerakoon K.C. (2007). Involvement of metabolic and sensitive acetylcholinesterase mecanisms in insecticide resistance of rice insect pest and predatory populations at Batalagoda, Sri Lanka. Journal of the National Science Foundation of Sri Lanka 35(2): $103-108$.

23. Karunaratne S.H.P.P., Weerakoon K.C., Nugaliyadda L. \& Manuweera G.K. (2007). Susceptibility of rice insect pests and their natural enemies to commonly used insecticides. Journal of the National Science Foundation of Sri Lanka 35(2): $97-102$.

24. Li Y., Dennehy T.J., Li X. \& Wigert M.E. (2000). Susceptibility of Arizona whiteflies to insecticides and IGRs: new developments in the 1999 season. Arizona Cotton Report. The University of Arizona College of Agriculture, Arizona, USA.

25. Li X., Degain B.A., Harpold V.S., Marcon P.G., Nichols R.L., Fournier A.J., Naranjo S.E., Palumbo J.C. \& Ellsworth P.C. (2012). Baseline susceptibilities of B and Q biotype Bemisia tabaci to anthranilic diamides in Arizona. Pest Management Science 68: 83 - 91. DOI: https://doi.org/10.1002/ps.2227

26. Mota-Sanchez D., Whalon M.E., Hollingworth R.M. \& Xue Q. (2008). Documentation of pesticide resistance in arthropods. Global Pesticides Resistance in Arthropods (eds. M. Whalon, D. Mota-Sanchez \& R. Hollingworth), pp. 32 - 39. Cromwell Press, Trowbridge, UK.

DOI: https://doi.org/10.1079/9781845933531.0032

27. Palumbo J.C., Horowitz A.R. \& Prabhaker N. (2001). Insecticidal control and resistance management for Bemisia tabaci. Crop Protection 20: 739 - 765.

28. Rauch N. \& Nauen R. (2003). Identification and biochemical markers linked to neonicotinoid cross resistance in Bemisia tabaci (Hemiptera: Aleyrodidae). Archives of Biochemistry and Physiology 54: $165-176$.

DOI: https://doi.org/10.1002/arch.10114

29. Roditakis E., Grispou M., Morou E., Kristoffersen J.B., Roditakis N., Nauen R., Vontas J. \& Tsagkarakou A. (2009). Current status of inseticde resistance in Q biotype 
Bemisia tabaci populations from Crete. Pest Management Science 65(3): 313 - 322 .

DOI: https://doi.org/10.1002/ps.1690

30. Servin-Villegas R., Garcia-Heenandez J.L., MurilloAmador B., Tejas A. \& Martinez-Carrillo Y.J.L. (2006). Stability of insecticide resistance of silverleaf whitefly (Homoptera: Aleyrodidae) in the absence of selection pressure. Folia Entomologica Mexicana 45(1): 27 - 34.

31. Sparks T.C. \& Nauen R. (2015). IRAC: mode of action classification and insecticide resistance management. Pesticide Biochemistry and Physiology 121: 122 - 128.

DOI: https://doi.org/10.1016/j.pestbp.2014.11.014

32. Tejeda A.L., Rodriguez-Maciel J.C. \& De Loera-Barocio
J.C. (2009). Susceptibility to insecticides in populations of Mexican arthropods. Agrociencia 43(2): 173 - 196.

33. Vassiliou V., Emmanouilidou M., Perrakis A., Morou E., Vontas J., Tsagkarakou A. \& Roditakis E. (2011). Insecticide resistance in Bemisia tabaci from Cyprus. Insect Science 18: 30 - 39.

DOI: https://doi.org/10.1111/j.1744-7917.2010.01387.x

34. Xie W., Liu Y., Wang S., Wu Q., Pan H., Yang X., Guo L. \& Zhang Y. (2014). Sensiitivity of Bemisia tabaci (Hemiptera: Aleyrodidae) to several new insecticides in China: effects of insecticide type and whitefly species, strain and stage. Journal of Insect Science 14: 261.

DOI: https://doi.org/10.1093/jisesa/ieu123 